\title{
PENGETAHUAN PERAWAT DALAM PENERAPAN K3 GUNA MENINGKATKAN MUTU PELAYANAN RS
}

\author{
Pebi Septrian Sari \\ febi.septrian03@gmail.com
}

\section{LATAR BELAKANG}

Rumah sakit merupakan sarana pelayanan yang bergerak dibidang pelayanan jasa kesehatan bagi masyarakat. Dalam pemberian pelayanan kesehatan, RS diharapkan dapat memberikan pelayanan yang berkualitas. Selain itu, sebagai salah satu fasilitas pelayanan kesehatan dapat menjadi tempat yang berbahaya dan berisiko tinggi untuk keselamatan kerja. Dengan itu, RS berkewajiban menerapkan pembinaan upaya Keselamatan dan Kesehatan Kerja Rumah Sakit (K3RS). Upaya ini diterapkan agar terhindar dari adanya risiko kecelakaan kerja.

Kesehatan dan Keselamatan Kerja (K3) merupakan suatu upaya perlindungan kepada tenaga kerja dan orang lain untuk menjauhkan segala risiko yang dapat terjadi pada diri sendiri maupun risiko yang dapat membahayakan pasien. Saat memberikan pelayanan kesehatan kepada pasien banyak risiko yang membahayakan seorang perawat dan pasien di rumah sakit. Jadi, Tujuan diterapkannya K3RS adalah terciptanya cara kerja, lingkungan kerja yang sehat, aman, nyaman, dan dalam rangka meningkatkan derajat kesehatan tenaga medis . Pengetahuan K3RS yang baik diharapkan mampu menekan angka kecelakaan kerja karena individu tersebut dapat menerapkan tindakan yang sesuai dengan pengetahuan K3 yang dimilikinya.

Sesuai Undang-Undang Republik Indonesia No. 23 Tahun 1992 tentang Kesehatan, Pasal 23 dinyatakan bahwa upaya Kesehatan dan Keselamatan Kerja (K3) harus diselenggarakan disemua tempat kerja, khususnya tempat kerja yang mempunyai risiko bahaya kesehatan dan mudah terjangkit penyakit dan Undang-Undang Nomor 36 Tahun 2009 tentang penerpan Kesehatan dan Keselamatan Kerja di rumah sakit. Segala hal yang menyangkut penyelenggaraan K3 di rumah sakit diatur dalam Keputusan Menteri Kesehatan Nomor 432 tentang pedoman Kesehatan dan Keselamatan Kerja di Rumah Sakit.

Perawat adalah salah satu tenaga pelayanan kesehatan yang berinteraksi dengan pasien secara berkesinambungan memberikan pelayanan keperawatan di rumah sakit secara terus menerus selama 24 jam yang berisiko mengalami penyakit dan kecelakaan kerja. Perawat dalam memberikan asuhan keperawatan memiliki hak untuk bekerja dengan aman sehingga dapat 
memberikan pelayananyang berkualitas kepada pasien (American Nurses Association,2007). Tingkat pengetahuan K3 perawat sangat penting dalam menjaga keselamatan pasien dan diri perawat itu sendiri sesuai dengan penelitian terdahulu bahwa ada hubungan bermakna antara tingkat pengetahuan perawat dengan tindakan keselamatan terhadap pasien.

Mutu pelayanan tidak hanya dilihat dari peningkatan keselamatan kerja, namun dilihat juga dari perilaku dan pengetahuan perawat dalam menjaga dirinya untuk terhindar dari segala bahaya dan kecelakaan saat bekerja. Untuk meningkatkan pengetahuan mengenai Kesehatan dan Keselamatan Kerja, maka rumah sakit memberikan pelatihan mengenai K3 agar seluruh tenaga kesehatan dapat mencegah dan menanggulangi bahaya yang terjadi. Langkah awal yang dapat dilakukan perawat untuk mencegah terjadinya infeksi yaitu menggunakan sarung tangan dan masker. Dengan perawat menerapkan K3 di rumah sakit dapat meningkatkan kualitas pelayanan.

\section{METODE}

Metode yang digunakan dalam penulisan ini menggunakan metode literature review, dengan cara membaca dan menganalisis bahan kajian yang erat kaitannya dengan pokok pembahasan yang berhubungan dengan Keselamatan,dan Kesehatan Kerja (K3) di rumah sakit. Bahan kajian yang digunakan berupa jurnal, artikel, textbook, maupun e-journal yang relevan. Adapun jurnal yang digunakan pada literature review ini, minimal menggunakan 10 referensi yang diterbitkan paling lama sepuluh tahun terakhir.

\section{HASIL}

Dari kajian ini didapatkan hasil, bahwa ada hubungan antara tingkat pengetahuan perawat mengenai penerapan K3. Tingkat pengetahuan dengan penerapan K3RS di RSUD Pobundayan Kota Kotamobagu. Hasil penelitiannya juga di dukung oleh penelitian yang dilakukan oleh pratama (2015) membuktikan bahwa terdapat hubungan yang bermakna antara tingkat pengetahuan dengan penerapan manajemen Keselamatan dan Kesehatan Kerja. Bahwa faktor pengetahuan perawat sangat berpengaruh dalam penerapkan K3 guna mengurangi penyakit akibat kerja atau kecelakaan akibat kerja dan meningkatkan mutu pelayanan rumah sakit. Untuk meningkatkan pengetahuan perawat maka rumah sakit memberikan pelatihan mengenai K3 mengingat kebanyakan kecelakaan kerja banyak terjadi.

\section{PEMBAHASAN}


Di dalam pelaksanaan Kesehatan dan Keselamatan Kerja (K3) di Rumah sakit. Penerapan K3 merupakan suatu bentuk pencegahan untuk menciptakan tempat kerja yang aman, sehat, dan nyaman, serta bebas dari pencemaran lingkungan sehingga bebas dari kecelakaan kerja maupun penyakit yang terjadi akibat kecelakaan kerja yang pada akhirnya akan meningkatkan efisiensi rumah sakit dan produktivitas kerja. Penyakit akibat kerja (PAK) dan Kecelakaan Kerja (KK) dikalangan petugas kesehatan. Sebagai faktor penyebabnya, sering terjadi karena kurangnya kesadaran pekerja dan kualitas serta keterampilan pekerja yang kurang memadai.

Keberadaan perawat di rumah sakit menempati urutan pertama dari segi jumlah dan segi pelayanan. Tingginya jumlah perawat merupakan kekuatan rumah sakit dalam memberi pelayanan. Didalam waktu kerja yang lama, Perawat juga memiliki angka kecelakaan kerja yang cukup tinggi dibandingkan dengan kecelakaan kerja tenaga kesehatan lain. ILO(International Labour Organization) merupakan suatu organisasi yang menaungi permasalahan K3 ditingkat dunia. Menurut ILO pelaksanaan K3 ini ditunjukan untuk mencegah kecelakaan dan penyakit yang ditimbulkan akibat kecelakaan kerja.

Perawat juga harus memiliki kemampuan kognitif. Kemampuan kognitif ini mempengaruhi kemampuan individu dalam melakukan tindakan yang tidak menimbulkan risiko terhadap keselamatan pasien. Cahyono (2008) menyatakan bahwa pengetahuan SDM kesehatan, termasuk perawat adalah hal yang berhubungan dengan komitmen yang sangat diperlukan dalam upaya untuk membangun budaya keselamatan pasien. Upaya meningkatkan pengetahuan tetap merupakan suatu hal yang penting dalam konteks keselamatan pasien.

Penerapan K3 dirumah sakit meliputi tenaga kerja, metode kerja, alat kerja, proses kerja, serta lingkungan kerja. Untuk menghindari kecelakaan dan bahaya perawat harus memiliki pengetahuan mengenai K3. Pengetahuan mengenai K3 perawat dipengaruhi oleh pengalaman baik pengalaman sendiri ataupun orang lain. Pengalaman perawat dapat dilihat dari berbagai aspek. Salah satunya adalah masa kerja. Semakin lama masa kerja perawat maka pengalaman yang dimiliki juga semakin meningkat sehingga perilakunya dalam menjaga keselamatan dirinya juga menjadi lebih baik. Selain itu pengalaman juga dapat diperoleh dari berbagai sosialisasi maupun pelatihan tentang K3 yang dilakukan oleh pihak rumah sakit.

Pengetahuan tentang K3 yang tergolong masih rendah diadakannya pelatihan K3 oleh perawat yang membentuk unit Kesehatan dan Keselamatan Kerja rumah sakit (K3RS) jika didalam suatu unit terdapat perawat yang belum sempat mengikuti pelatihan K3 maka wajib melaporkan ke departemen K3 rumah sakit dan segera memasukan perawat tersebut ke 
pelatihan yang akan diadakan berikutnya. Depkes (2009) juga menekankan mengenai melaksanakan pendidikan, pelatihan ataupun promosi kesehatan kerja secara berkala dan berkesinambungan sesuai kebutuhan dalam rangka menciptakan budaya K3 di rumah sakit. Dan tingkat pengetahuan juga mempengaruhi komunikasi teraupetik perawat. Komunikasi teraupetik juga termasuk program K3 rumah sakit.

Perawat dapat melakukan tindakan untuk meningkatkan penerapan $\mathrm{k} 3$ di rumah sakit yaitu dengan melakukan tahap tindakan program K3Rs yaitu; pelaksanaan kesehatan kerja bagi karyawan (pekerja,berkala,dan khusus), upaya mengamankan pasien (menjalankan sistem keselamatan pasien), sanitasi lingkungan RS, pengolahan limbah padat, cair, gas. Pengumpulan, pengolahan, dokumentasi data dan pelaporan K3RS.

Pencegahan kecelakaan kerja dapat dilakukan juga dengan menerapkan pelaksanaan sesuai dengan SOP secara benar di tempat kerja dan penggunaan alat pelindung diri bagi tenaga kesehatan salah satunya ialah perawat. Pencegahan ke kecelakaan kerja dapat dilakukan dengan (1) pengamatan resiko bahaya di tempat kerja, (2) melakukan setiap tindakan dan pelaksanaan sesuai dengan SOP secara benar di tempat kerja, (3) pengendalian faktor bahaya di tempat kerja, (4) peningkatan pengetahuan tenaga kerja terhadap keselamatan kerja dan (5) pemasangan peringatan bahaya kecelakaan di tempat kerja. Selain itu upaya pencegahan kecelakaan kerja juga perlu disediakan sarana untuk menanggulangi apabila terjadi kecelakaan kerja, contohnya seperti penyediaan $\mathrm{P} 3 \mathrm{~K}$, penyediaan peralatan dan perlengkapan tanggap darurat.

Selain itu, Langkah awal agar pengendalian berbagai risiko Kesehatan dan Keslamatan Kerja untuk perawat di rumah sakit agar berhasil optimal maka perlu dibudayakan K3 diberbagai bagian rumah sakit. Sesuai dengan pendapat Mulyati dkk. (2016) bahwa budaya Kesehatan dan Keselamatan Kerja di Rumah Sakit merupakan kunci untuk tercapainya peningkatan Kesehatan dan Keselamatan Kerja dalam organisasi.

\section{PENUTUP}

Pentingnya pengetahuan Kesehatan dan Keselamatan Kerja oleh perawat di rumah sakit guna meningkatkan mutu pelayanan. Perawat dalam menjalankan tugasnya di rumah sakit harus memiliki pengetahuan yang baik untuk menerapkan K3 di rumah sakit. Karena perawat salah satu tenaga kesehatan yang memberi pelayanan kesehatan yang lebih lama berinteraksi dengan 
pasien untuk meningkatkan dan memenuhi rasa aman, nyaman ,dan keselamatan pasien selama berada ditempat kerja dengan tetap melakukan asuhan keperawatan sesuai dengan SOP.

\section{DAFTAR PUSTAKA}

Putri, S., Santoso \& Rahayu, P, E. (2018). Pelaksanaan Keselamatan Dan Kesehatan Kerja Terhadap Kejadian Kecelakaan Kerja Perawat Rumah Sakit. Jurnal Endurance. Vol 3(2). 271 277.

Nazirah, R \& Yuswardi. (2017). Perilaku Perawat Dalam Penerapan Manajemen Kesehatan Dan Keselamatan Kerja (K3) di Aceh. Idea Nursing Journal. Vol 8(3).

Tukatman., Sulistiawati., Purwaningsih., \& Nurusalam. (2015). Analisis Keselamatan Dan Kesehatan Kerja Perawat Dalam Penanganan Pasien Di Rumah Sakit Benyamin Guluh Kabupaten Kolaka. Jurnal Ners. Vol 10(2). 343-347.

Yulia, S., Hamid, Y, S, A \& Mustikasari. (2012). Peningkatan Pemahaman Perawat Pelaksana Dalam Penerapan Keselamatan Pasien Melalui Pelatihan Keselamatan Pasien. Jurnal Keperawatan Indonesia. Vol 15(3). 185-192.

Maringka, F., Kawatu, A, T, P \& Punuh, I, M. (2019). Analisis Pelaksanaan Program Kesehatan Dan Keselamatan Kerja Rumah Sakit (K3RS) Di Rumah Sakit Tingkat II Robert Wolter Mongisidi Kota Manado. Jurnal KESMAS. Vol 8(5). 1-10.

Ramdan, M, I \& Rahman,A. (2017). Analisis Risiko Kesehatan Dan Keselamatan Kerja (K3) Pada Perawat. JKP. Vol 5(3). 229-241.

Hanifa, D, N., Respati, T \& Susanti, Y. (2017). Hubungan Pengetahuan Dengan Upaya Penerapan K3 Pada Perawat. Bandung Meeting on Global Medicine \& Health (BaMGMH). Vol 1(1). 144-149.

Ivana, A., Widjasena, B \& Jayanti, S. (2014). Analisa Komitmen Manajemen Rumah Sakit (RS) Terhadap Keselamatan Dan Kesehatan Kerja (K3) Pada RS Prima Medika Pemalang. Jurnal Kesehatan Masyarakat (e-Journal). Vol 2(1).35-41. 
Cahyono, S.B.(2008). Membangun Budaya Keselamatan Pasien Dalam Praktik Kedokteran. Yogyakarta: Kanisius.

Simamora, R. H. (2018). Buku ajar keselamatan pasien melalui timbang terima pasien berbasis komunikasi efektif: SBAR. Medan: USUpress.

Simamora, R. H. (2019). Buku ajar pelaksanaan identifikasi pasien. Uwais Inspirasi Indonesia. 